\title{
sciendo

\section{Design and Simulation of a Solar Energy System for Desalination of Brackish Water}

\author{
Hind ENNASRI ${ }^{1 *}$, Asmaa DRIGHIL ${ }^{2}$, Rahma ADHIRI $^{3}$, Ahmed FAHLI $^{4}$, \\ Mohamed MOUSSETAD ${ }^{5}$ \\ ${ }^{1-3,5}$ Laboratory of Engineering and Materials, Faculty of Sciences of Ben M'sik, Hassan II University, \\ Boulevard CdtDriss El Harti, Casablanca, B.P.-7955, Morocco \\ ${ }^{4}$ Hassan I University, Ibnou Lhaytham Street, Settat, B.P.-577, Morocco
}

\begin{abstract}
In light of a sort of crisis of water scarcity which begins to loom worldwide as well as the economic constraints for achieving sustainable development, it becomes essential to find appropriate solutions to face this challenge. Morocco, which has considerable brackish water resources and an important solar resource deposit, is required to use desalination techniques; however, the reliability of such techniques can no longer be applied just in terms of their value as renewable sources of energy. The solution presented in this publication, establishes a rather reliable way to produce drinking water. The technique of desalination by reverse osmosis is considered in this study to be a promising technique. The objective of our study is the implementation of a prototype for desalination of reverse osmosis, which is a low-cost small unit used to treat brackish water based on solar energy.
\end{abstract}

Keywords - Desalination; reverse osmosis; solar energy; water

\section{INTRODUCTION}

The socio-economic conditions associated with water usage have dramatically changed under the pressures of a rapidly evolving demography, continuous development of the living conditions of populations, accelerated growth, introduction of large-scale irrigation, and the development of industries [1], [2].

This fast-socio-economic advancement has resulted in increasing pressure on water resources. In Africa, according to predictions, water shortages threaten the north of the continent in particular. In Morocco, more water will be needed in 2040 than the amount which will likely be available [3]. This shortage produces the need to increase traditional water supply via alternative sources. The availability of saline water sources (i.e., seawater or brackish water) via membrane separation is one such alternative desalination solution. Despite major advancements in desalination technologies, seawater desalination is still more energy intensive compared to conventional technologies used in fresh water treatment. There are also some concerns about the potential environmental impacts of large-scale seawater or brackish water desalination plants [4].

Desalination systems fall into two main thermal types: multi-flash distillation MSF, multi-effect evaporation MED and mechanical compression of steam MVC. In addition,

\footnotetext{
* Corresponding author.

E-mail address: hindennasri@ gmail.com
} 
desalination by a membrane process is obtainable through reverse osmosis and electrodialysis [5].

The efficiency of each type is relative to the total energy prerequisite to eliminate the particles of salt depending on the method of functioning used, as well as the purity of the required water. Reverse Osmosis (RO) is the most widely used method in the world: in order to operate this technology, it is necessary to think about the source of energy used as well as the amount of reverse osmosis required energy. Thus, it is the only electricity consumed mainly by high pressure pumps [6]. Such energy plays a very important role in the cost of producing fresh water from seawater or brackish water. Typically, in a RO plant, the production of one cubic meter of fresh water from seawater uses between 3 and $10 \mathrm{kWh}$ of electricity and between 0.5 and $2.5 \mathrm{kWh}$ of brackish water [7], [8].

Lately, the world has been facing the problem of fossil fuel depletion and the challenge of climate change. It follows that it is a prerequisite to use renewable energy in order to reduce the cost of desalination to save energy, and to ensure availability of free energy. Numerous countries in the world have built renewable energy reverse osmosis units of small and medium capacity $0.5-50 \mathrm{~m}^{3} / \mathrm{d}$ [9]. Small units demand energy varying mainly depending on the nature of water, for the operating pressure which varies between 10 and 15 bar for brackish water and between 55 and 65 bar for seawater [10].

In Morocco, the potential of solar energy is very important, and it is used effectively in small units. In this regard, it is worth mentioning the example of the work of the Faculty Samlaliya research team in Marrakech that led to the installation of two units of desalination in two different villages of Morocco (Tamguerte rural municipality, Alhouez province and Had Draa rural municipality of Essaouira province) in order to provide drinking water to local inhabitants. These desalination units, which are powered by a photovoltaic installation of 3.9 and $4.8 \mathrm{~kW}_{\mathrm{p}}$, have a production capacity of $1 \mathrm{~m}^{3} / \mathrm{h}$ [11]. Another example is in Malaysia where a photovoltaic (PV) power system of $2 \mathrm{~kW}_{\mathrm{p}}$ has been installed, knowing that the feed water contains salinity which is equal to $2000 \mathrm{mg} / \mathrm{l}$. The amount of fresh water produced per day by this unit is $5.1 \mathrm{~m}^{3}$ with a specific energy of $1.1 \mathrm{kWh} / \mathrm{m}^{3}$ [12].

The objective of our study is to achieve a prototype of brackish water desalination, which is based on solar energy. For this end, the desalination unit is required to be miniaturized, portable and of low cost.

With a view to answer this problem, emphasis in our study is placed initially on the design of the reverse osmosis system, so as to minimize the size of the unit. Secondly, we aim to develop the proposed system in order to increase the production of freshwater.

\section{Potential of Brackish Water in Morocco}

Water plays a central role in all aspects of life, and it becomes one of the paramount environmental issues facing the next generation. Presently, freshwater resources have become insufficient or non-sufficient due to demographic and industrial expansion. Freshwater resource shortage is a major problem in the world's arid regions. More than $97 \%$ of the water on the Earth's surface is salt water; the desalination of this water presents an alternative solution to afford water for drinking and irrigation purposes. In our case, the distribution of groundwater potential in Morocco as a whole is $4025 \mathrm{Mm}^{3}$. Morocco suffers from the issue of water shortage, but thanks to the exploitation of unusable brackish water, we can solve this problem, especially in isolated areas. The table below shows the distribution of brackish water and its salinity in the different regions of Morocco [13]. 
TABLE 1. THE POTENTIAL OF BRACKISH WATER IN MOROCCO

\begin{tabular}{lll}
\hline Region & Potential, $\mathrm{Mm}^{3}$ & Salinity, g/l \\
\hline Kert & 14 & 0.6 to 10 \\
Gareb et BouAreg & 52 & 6 to 8 \\
RhisNeckor & 17 & 2 to 5 \\
Triffa & 50 & Can reach $8 \mathrm{~g} / \mathrm{l}$ \\
Guercif & 40 & 2 to 5 \\
Chaouia & 44 & 2 to 10 \\
Gharb & 75 & 2 to 10 \\
Sahel & 60 & 2.9 \\
Crétacéd'Errachidia & 29 & 2 to 13 \\
Ain El Ati & 7 & 4 to 14 \\
Tafilalet & 22 & 0.6 to 10 \\
Tarfaya & 10 & 3.5 on average \\
Foum El Oued & 4 & 3 to 8 \\
Crétacé(Sahra) & 13 & 2 to 3 \\
Average ValléeDraa & 60 & 0.5 to 16 \\
Total & 497 & \\
\hline
\end{tabular}

\section{Potential of Solar Energy in Morocco}

Energy is consumed in different forms such as electricity, heat, fuel and gas, given that the solar radiation that reaches the Earth represents in one year more than 5000 times the world energy consumption. The time span of the Sun is estimated at 5 billion years, which makes it a sustainable energy source.

Solar radiation is certainly the most key source of renewable energy, and Morocco has very interesting solar energy potential, including an average exposure to solar radiation ranging from 4.7 to $5.6 \mathrm{kWh}$ per day and per square meter and a number of hours of sunshine that oscillates between 2800 and 3400 hours/year, depending on the region [14].

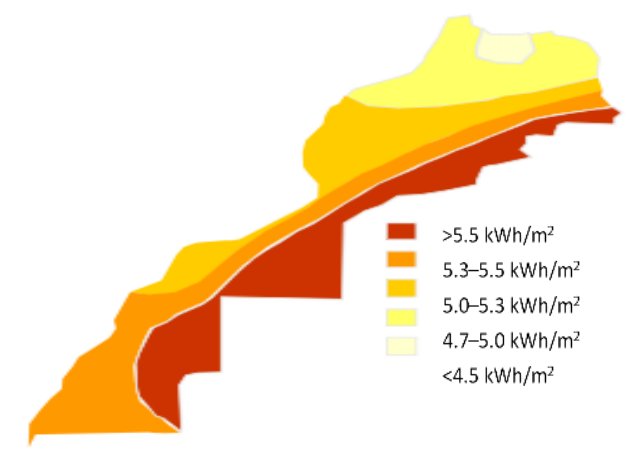

Fig. 1. Solar irradiation map of Morocco (MASEN) [15]. 


\section{Membrane Processes}

Membrane processes are used to separate and concentrate molecules or ionic species in solution and/or to separate particles or microorganisms suspended in a liquid; these processes are based on the implementation of permselective membranes [16].

Membrane separations are based on the concept of selective displacement of certain components through a membrane [17].

Most of the separation and/or concentration operations use tangential filtration; or the treated fluid tangentially circulates into the membrane (filter) to limit the accumulation of material resulting from the transversing the flow generated by pressure gradient [18].

The feed stream components passing through the membrane are known as "permeate"; the retained fluid, which is called "retentate", constitutes the flow containing the components that cannot cross the membrane [19].

The term membrane technology is a generic term that encompasses different separation processes. These methods belong to the same type because a membrane is used in each of them. Membranes are increasingly used for treatment processes. The reasons behind this tremendous industrial success are as follows:

- Their low energy consumption (i.e., micro and tangential ultrafiltration 1 to $15 \mathrm{~kW} / \mathrm{h} / \mathrm{m}^{3}$ permeate, nanofiltration 3 to $7 \mathrm{~kW} / \mathrm{h} / \mathrm{m}^{3}$ and reverse osmosis $940 \mathrm{~kW} / \mathrm{h} / \mathrm{m}^{3}$ ) [20], and their relatively good selectivity [21]; it is for this reason that the environment and water treatment sectors have adopted such technologies in recent years [22];

- The best quality of the products; the membrane is a physical filter that works without adding chemical products and constitutes an absolute barrier for many of the compounds [23];

- The ease of industrial integration and reliability [20];

- Clean technology intervenes preventively upstream from the production stage, which distinguishes it from the conventional clean-up operation that occurs downstream in this process (water treatment [18], gaseous effluents, and solids). The objective is to reduce the consumption of water, raw materials, and energy in order to generate a minimum of effluents and waste, and thus to save money, something which leads to longer investment returns;

- Innovation in products and processes responding to consumer demand for variety and specificity [20].

The use of desalination is essential in the southern areas of Morocco, which are characterized by an arid climate. In 1975, the first unit of drinking water production by desalination of brackish water with $5 \mathrm{~g} / \mathrm{l}$ of salinity was commissioned in Tarfaya, by electrodialysis; this unit was replaced in 1983 by reverse osmosis with a capacity of $125 \mathrm{~m}^{3} /$ day [24]. The National Office of Drinking Water (ONEP) in Morocco was forced to permit expansion of reverse osmosis salt water desalination plants, and even to plan to build others in the next two decades. The construction and operation of these desalination units has made it possible to invest in the know-how and ensure the introduction of the most adapted techniques in Morocco [25]. Desalination by membrane processes has shown its effectiveness throughout the world. Numerous laboratory-scale works have been carried out with regard to brackish water desalination and industrial effluents [26], [27].

Reverse osmosis is the most widely used water desalination process (Fig. 2). Up to $65 \%$ of desalinated water is operated by RO; the rest is achieved by thermal processes such as multi-stage flash (MSF), multi-effects distillation (MED), vapor compression (VC) and 
desalting by adsorption (DA) [28], [29]. The advantage of OI desalination is attributed to its low cost, low energy demand and improved durability.

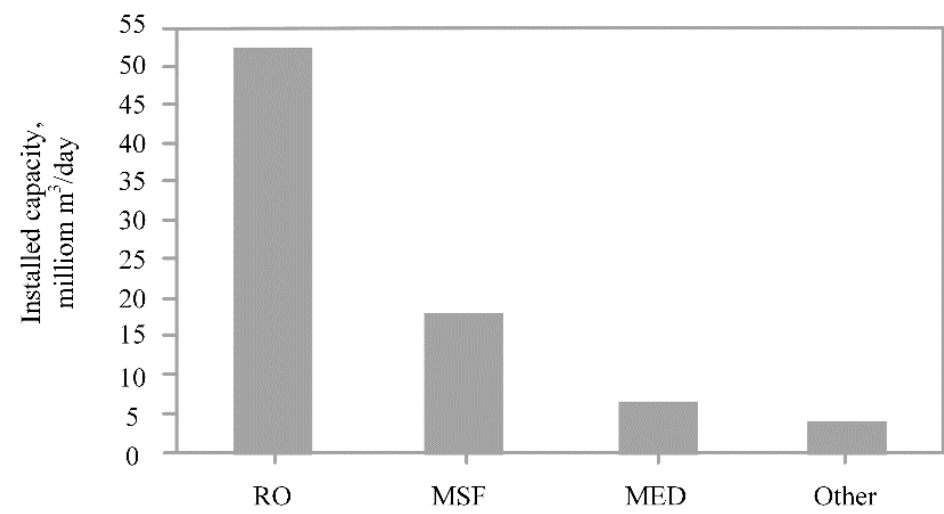

Fig. 2. Total desalination capacity installed worldwide by technology in 2013 [30].

\section{Renewable Energy Desalination}

Renewable energy resources in water desalination and purification have become more significant for the following reasons: the increase of conventional systems costs, and the commitments to reduce greenhouse gas emissions and the operating targets of renewable energy. Thus, solar energy could be a sustainable alternative for the operation of desalination plants or units, especially in countries which are on the solar belt such as India, China, as well as the African and Middle East countries [31], [32].

Various renewable energy sources are available in different parts of the world. The main renewable energy sources used for desalination are solar energy, wind power, and geothermal energy. Table 2 shows some renewable energy desalination plants in different countries.

TABle 2. Selected Renewable EnERgy Desalination Plants [33]

\begin{tabular}{lllll}
\hline $\begin{array}{l}\text { Desalination plant } \\
\text { name }\end{array}$ & Location & $\begin{array}{l}\text { Desalination } \\
\text { technology }\end{array}$ & Capacity, $\mathrm{m}^{3} / \mathrm{d}$ & $\begin{array}{l}\text { Renewable energy } \\
\text { source }\end{array}$ \\
\hline Kimolos & Greece & MED & 200 & Geothermal \\
Keio University & Japan & MED & 100 & Solar collectors \\
PSA & Spain & MED & 72 & $\begin{array}{l}\text { Concentrating solar } \\
\text { power (CSP) }\end{array}$ \\
Ydriada & Greece & RO & 80 & Wind turbine \\
Morocco & Morocco & RO & $12-24$ & Photovoltaics (PV) \\
Oyster & Scotland & RO & n/a & Wave energy \\
\hline
\end{tabular}

The choice of appropriate energy source for desalination technologies, which is reverse osmosis in our case, depends on a number of factors. These include the size of the facility, salinity of water, availability of electricity to the electricity grid, technical infrastructure, in addition to the type and potential of desalination and renewable energy technologies; some of them seem to be more promising in terms of their economic and technological feasibility 
than others. However, their applicability strongly depends on the local availability of renewable energy resources and the quality of the water to be desalinated.

Most of these areas are rich in terms of seawater and brackish water, but they suffer at the same time from a lack of fresh water, making desalination by solar energy one of the most reliable solutions to meet their freshwater needs. Because of its abundant availability and its conversion flexibility into electrical or thermal energy, solar energy has been the main objective of desalination by renewable energies.

Moroccan experience in water desalination is strongly linked to socio-economic development. Morocco has accumulated real experience in the construction and operation of several desalination units, particularly in its coastal regions, as is the case in the southern provinces for reasons related to the arid climate and scarcity of conventional water resources in this area.

The development of renewable energy, which aims to secure supply, ensure availability and reduce the country's energy dependence, is one of Morocco's national priorities, Future economic projects are expected to lead to an increase in energy demand by 2030 . To support the acceleration of these projects, Morocco has developed an ambitious energy strategy for 2020-2030 [34].

Morocco is a geographically and climatically favoured country to develop the exploitation of renewable energy on a large scale. Since the second oil shock, Morocco has begun to focus on renewable energy. The Moroccan territory benefits from abundant sunshine which constitutes an exceptional opportunity in the current context of the development of solar technologies such as solar desalination. With more than $3000 \mathrm{~h} / \mathrm{year}$ of sunshine, or an irradiation of about $5 \mathrm{kWh} / \mathrm{m}^{2} /$ year, Morocco enjoys a sizeable solar field [35].

\section{Comparison of Reverse OSMosis With Other Processes}

Membrane processes involve electrodialysis, which is used mainly for brackish water, and reverse osmosis which is used for both brackish water and seawater. Table 3 bellow summarizes some comparisons.

TABle 3. COMPARISON OF MEMbrane Processes [36]

\begin{tabular}{lll}
\hline Nominations & Processes & \\
& RO & ED \\
\hline Energy used & Mechanical (via electricity) & Electric \\
Operating temperature, ${ }^{\circ} \mathrm{C}$ & $<45$ & $<45$ \\
Power consumption, $\mathrm{kWh} / \mathrm{m}^{3}$ & $4-7$ & 1 \\
Salinity of raw water, $\mathrm{g} / \mathrm{l}$ & $1-45$ & $0.1-3$ \\
Salinity of treated water, $\mathrm{mg} / \mathrm{l}$ & $<500$ & $<500$ \\
Advantage & Modularity & \\
\hline
\end{tabular}

It appears from Table 3 that electrodialysis is a competitor to OI which is only below a salt concentration of $3 \mathrm{mg} / \mathrm{l}$ in water.

Reverse osmosis is now a vital rival of distillation. It is necessary to recognize that, compared to distillation, the reverse osmosis technique has a number of advantages, including:

- Low energy consumption thanks in particular to the setting up of an energy recovery 
system and increased conversion rates;

- Lower base investments due in particular to increased performance membranes and a significant decrease in their cost;

- Range of very large capacity ranging between a few litres/day for survival appliances and more than $120000 \mathrm{~m}^{3} /$ day for the facilities of Medina in Saudi Arabia [37].

Desalination by distillation (MED and MSF) consumes energy mainly in the form of heat, and little electrical energy is required for pumps and auxiliaries; on the contrary, reverse osmosis uses only electrical energy.

\section{DEFINITION OF REVERSE OSMOSIS}

Osmosis is the transfer of solvent through a membrane under the effect of a concentration gradient. Considering a two-compartment system separated by a semi-permeable membrane, selective and containing two solutions of different concentrations, osmosis results in a directed flow of water from the diluted solution into the concentrated solution.

If pressure is applied to the concentrated solution, the amount of water transferred by osmosis will decrease. With a sufficiently high pressure, the flow of water will even be cancelled out; this pressure is called the osmotic pressure $\mathrm{P}$ (assuming that the diluted solution is pure water). If the value of the osmotic pressure is exceeded, a flow of water running in the opposite direction of the osmotic flow is observed; the phenomenon is termed reverse osmosis [38].

In reverse osmosis, solvent and solute transfers are made by solubility-diffusion; all the molecular species (solute and solvent) dissolve through the membrane and diffuse inside it in a liquid under the action of concentration and pressure gradient. The transfer, therefore, no longer depends on the particle size but on their solubility in the membrane medium.

The desalination of seawater or brackish water by reverse osmosis is achieved by applying to the desalting solution a pressure greater than the osmotic one under the effect that makes water flow through a semi-permeable membrane in the opposite direction (from the compartment containing salt water to the fresh water compartment). This process is simple but poses a real problem in terms of membrane fouling, which requires an extensive pre-treatment of seawater but light for brackish water.

Prior to chemical pre-treatment, the feed water is filtered to remove suspended solids and particles larger than 10 microns. Chemical pre-treatment includes the addition of sodium hypochlorite for the prevention of the growth of microorganisms, ferric chloride as flocculent, sulfuric acid for $\mathrm{pH}$ adjustment, and sodium bisulfite for reduction of chlorine. The flow of water through reverse osmosis modules is provided by high pressure pumps.

\section{Working Principle}

Water desalination involves extracting fresh water from salt water. All desalination processes involve three liquid streams, these are: feed water (brackish water), fresh water produced at low salinity, and discharge of concentrated water or brine. Reverse osmosis is a process that separates two solutions within different concentrations through a semi-permeable membrane. The main components of the reverse osmosis system are as follows: reverse osmosis module or membrane, high pressure pumps, electric power sources, energy recovery devices as needed, and a water pre-treatment system as shown in Fig. 3. The energy 
requirements of a reverse osmosis system are controlled by two major factors, which are the membrane properties and feed water salinity [39].

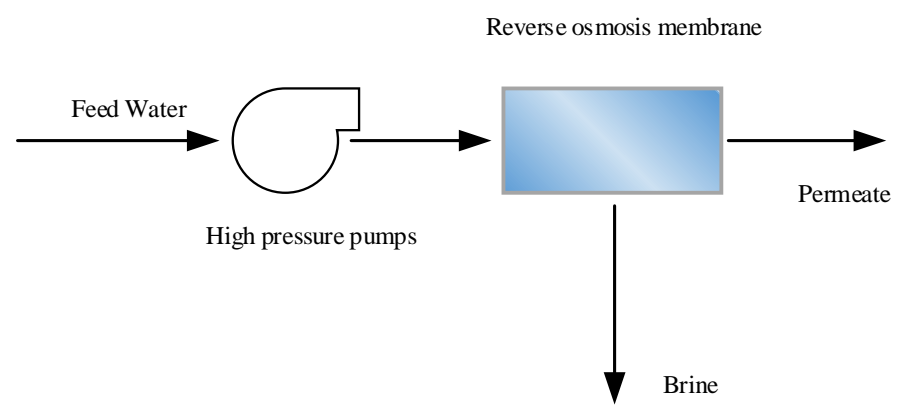

Fig. 3. Diagram of a reverse osmosis system.

\section{DESCRIPTION AND SYSTEM DESIGN}

Our installation consists of numerous parts:

- Pre-treatment system;

- Low pressure pump;

- High pressure pump;

- Reverse osmosis membrane;

- Photovoltaic module.

\subsection{Pre-Treatment System}

Pre-treatment of brackish water before reverse osmosis is absolutely necessary since reverse osmosis membranes are very sensitive to clogging, and good water quality at the inlet of reverse osmosis modules is essential to ensure stable performance of reverse osmosis in the long run.

The pre-treatment aims at increasing the membrane's life span, improving the produced water quality, maintaining the reverse osmosis performance and reducing clogging [40].

Pre-treatment processes can be divided into two categories: physical pre-treatment and chemical pre-treatment.

Physical pre-treatment includes mechanical pre-filters, cartridge filters, sand filtration and membrane filtration [40].

Chemical pre-treatment consists of the addition of scaling inhibitors, coagulants or disinfectants [41].

\subsection{Low Pressure Pump}

A low-pressure pump is a pump feeding the unit from the brackish water storage receiver with a nominal flow rate of $30-801 / \mathrm{min}$. The characteristics of the pressure pump are shown in Table 4 [42]. 
TABLE 4. CHARACTERISTICS OF PRESSURE PUMP

\begin{tabular}{ll}
\hline Characteristic & Value \\
\hline Nominal power & $370 \mathrm{~W}$ \\
Nominal voltage & $230 \mathrm{~V}$ \\
Rated current & $2.51 \mathrm{~A}$ \\
Nominal frequency & $50 \mathrm{~Hz}$ \\
Rated speed & $2820 \mathrm{tr} / \mathrm{min}$ \\
Rated flow & $30-80 \mathrm{l} / \mathrm{min}$ \\
Nominal pressure & $1.3-2 \mathrm{bar}$ \\
\hline
\end{tabular}

\subsection{High Pressure Pump}

High-pressure pump signifies the heart of the installation; its role resides in water supply inside the membrane with a required pressure (high pressure). We must calculate the hydraulic power required in order to be able to estimate the appropriate engine that runs the pump. This step consists of determining a maximum flow of $1200 \mathrm{l} / \mathrm{h}$ and a maximum pressure of 16 bar.

\subsubsection{Hydraulic Power}

$$
P_{\text {hydraulic }}=\frac{\operatorname{debit}(\mathrm{gpm}) \cdot \operatorname{pressure}(\mathrm{psi})}{1714 \cdot \eta}
$$

where $\eta$ is the efficiency of the engine [43].

\subsubsection{Electric Power}

$$
P_{\text {electric }}=\frac{P_{\text {hydraulic }}}{\eta_{\mathrm{m}}},
$$

where $\eta_{m}$ the electric efficiency of the motor.

\subsection{Reverse Osmosis Membrane}

The reverse osmosis membrane is a type of membrane which is a spiral-wound configuration; two flat sheets of membrane are separated by a permeate collector channel material to form a leaf. This assembly is sealed on three sides, while the fourth side is left open to permeate to the exit. A feed/brine spacer material sheet is added to the leaf assembly. A number of these assemblies or leaves are wound around a central plastic permeate tube. These tubes are perforated to collect the permeate from multiple leaf assemblies. The typical industrial spiral-wound membrane element is approximately 100 or $150 \mathrm{~cm}$ long and 10 or $20 \mathrm{~cm}$ in diameter.

The membrane used is the spiral type; we choose the membrane manufactured by Filmetec under the trade name Filmetec BW30-400 because this membrane is characterized by its chemical, thermal and microbiological stability, as well as its hydraulic resistance. The membrane specifications are illustrated below [44]. 
TABLE 5. SPECIFICATIONS OF THE MEMBRANE

\begin{tabular}{ll}
\hline Specification & Value \\
\hline Product & BW 30-400 \\
Stabilized salt rejection, \% & 99.5 \\
Permeate flow rate, $\mathrm{m}^{3} / \mathrm{d}$ & 40 \\
Active area, $\mathrm{m}^{2}$ & 37 \\
Maximum operating pressure, bar & 41 \\
Maximum operating temperature, ${ }^{\circ} \mathrm{C}$ & 45 \\
\hline
\end{tabular}

\subsection{Photovoltaic Module}

Consisting of a semiconductor material, photovoltaic panels produce electricity from the electrical voltage created by a shock between the photons and particles that carry solar energy and the electrons of the atoms constituting the material of the photovoltaic panel. The operation of these panels is based on a physical phenomenon known as photoelectric effect.

The reverse osmosis process requires electrical energy to operate the pumps at high and low pressure. The source of electrical energy in our desalination unit is photovoltaic solar energy. Our unit contains 6 photovoltaic panels, with a nominal power of $300 \mathrm{~W}$ for each. The parameters of the photovoltaic module are as summarized in Table 6 [45].

TABle 6. Parameters of a Photovoltaic Module

\begin{tabular}{ll}
\hline Electrical Characteristic & Value \\
\hline Nominal power & $300 \mathrm{~W}$ \\
Panel performance & $18.45 \%$ \\
Cell type & Monocrystalline silicon \\
Voltage & $32.94 \mathrm{~V}$ \\
Current & $9.11 \mathrm{~A}$ \\
Short-circuit current & $9.63 \mathrm{~A}$ \\
Open-circuit voltages & $40.71 \mathrm{~V}$ \\
\hline
\end{tabular}

\section{Modelling of Desalination Unit}

In the case of reverse osmosis, solvent and solute transfers are achieved by solubility diffusion. In all molecular species (solute and solvent) dissolve and diffuse inside the membrane as a solid or liquid under the action of a pressure concentration gradient. The solvent and solute flow through the membrane are given respectively by [46]:

$$
\begin{aligned}
& J_{\mathrm{W}}=A \cdot(\Delta P-\Delta \pi), \\
& J_{\mathrm{s}}=B \cdot\left(C_{\mathrm{m}}-C_{\mathrm{p}}\right) .
\end{aligned}
$$


The terms of $\Delta P$ and $\Delta \pi$ constitute the transmembrane pressure (applied pressure) and the osmotic pressure difference across the membrane, with respectively $A$ and $B$ permeability of the membrane to water and salt, the $C_{\mathrm{m}}$ and $C_{\mathrm{p}}$ are respectively the solute concentration of the feed and permeate on both sides of the membrane.

The fluid and solute mass balance equations are:

$$
\begin{gathered}
Q_{\mathrm{a}}=Q_{\mathrm{p}}+Q_{\mathrm{r}}, \\
Q_{\mathrm{a}} \cdot C_{\mathrm{a}}=Q_{\mathrm{p}} \cdot C_{\mathrm{p}}+Q_{\mathrm{r}} \cdot C_{\mathrm{r}},
\end{gathered}
$$

where $Q_{\mathrm{a}}, Q_{\mathrm{p}}, Q_{\mathrm{r}}$ flows are feed water, fresh water (permeate), concentrated water (brine) with their concentrations $C_{\mathrm{a}}, C_{\mathrm{p}}, C_{\mathrm{r}}$.

The relationship between salt water concentration and osmotic pressure is linear. The osmotic pressure $\Pi$, is calculated by the following correlation [47]:

$$
\Pi=\alpha \cdot C
$$

where $\alpha=7.79 \cdot 10^{4} \mathrm{~Pa} / \mathrm{kg} \cdot \mathrm{m}^{-3}$.

The flow produced by the RO unit can therefore be deduced from the following relation:

$$
Q_{\mathrm{p}}=\frac{P_{u} \cdot \eta_{\mathrm{p}}}{\Delta P}
$$

where

$P_{u} \quad$ Power supplied or produced, W;

$\eta_{\mathrm{p}} \quad$ Efficiency of the pump;

$\Delta P \quad$ Applied pressure.

The effect of temperature on the permeability of the membrane to the solvent, $A(T)$, and the permeability of the solute membrane, $B(T)$, is estimated by the following relations [48]:

$$
\begin{gathered}
A(T)=\frac{A_{0} \cdot \mu\left(T_{0}\right)}{\mu(T)} \\
B(T)=\frac{B_{0} \cdot(T+273.15) \cdot \mu\left(T_{0}\right)}{T_{0} \cdot \mu(T)} .
\end{gathered}
$$

The dependence of temperature on viscosity is approximately calculated by the Guzman Andrade equation [49]:

$$
\mu(T)=1.984 \cdot 10^{-6} \exp \left[\frac{1825.85}{T+273.15}\right]
$$


RO system performance depends on the conversion rate of RO module, which could be defined as the ratio between the flow of fresh water and that of brackish water [50]:

$$
y=\frac{Q_{\mathrm{p}}}{Q_{\mathrm{a}}} .
$$

Percentage of salt rejection $R$, is then calculated from [41]:

$$
R=\frac{1-C_{\mathrm{p}}}{C_{\mathrm{a}}} \cdot 100 .
$$

In a reverse osmosis process without installation of the energy recovery system, energy consumption specific to the production of one cubic meter of fresh water is given by [51]:

$$
E=\frac{W_{\text {pump }}}{36.6 \cdot \eta_{\mathrm{p}} \cdot Q_{\mathrm{p}}} .
$$

The work of the high-pressure pump is given by the following relation:

$$
W_{\text {pump }}=P_{\mathrm{a}} \cdot Q_{\mathrm{a}}
$$

\section{RESULTS AND INTERPRETATIONS}

The availability of solar energy remains intermittent, with strong variations in intensity: there are periods when the sun is stronger, and others when it cannot be used. Sunshine can vary depending on time as well as the region where one is located. However, it is the amount of sunshine that would depend on the amount of the energy supplied. Therefore, the interest of using this energy varies, and its economy and profitability change according to the time and place where one is located. Solar radiation that arrives onto the ground decomposes into two parts: one comes directly from the sun (direct), whereas the other is diffused by the atmosphere (diffuse). Atmosphere and earth also have a clean radiance. The knowledge of these various radiations makes it possible to establish a radiative balance of the earth-atmosphere system.

When solar radiation propagates in the atmosphere, it interacts with its gaseous constituents and with all the particles present in suspension. The particles in question have some dimensions varying between one hundred of a $\mu \mathrm{m}$ and a few hundred of $\mu \mathrm{m}$. Solar radiation can be reflected, scattered or absorbed.

Whatever the season, it can be seen at sunset when the illumination decreases and becomes colder than during the day. The light reappears every morning at sunrise and the temperature rises. The Sun is therefore the source of light and heat on the Earth. The higher it is in the sky, the higher the illumination becomes.

Desalination by renewable energy, mainly solar energy, is influenced by several parameters. Desalination by photovoltaic technology is a technology that respects the environment. In addition, desalination through renewable energy can help reduce the need for 
fossil fuel imports and can also provide solutions for the agricultural sector, such as irrigation water supply.

Fig. 4 represents the daily global radiation in Casablanca which is located in the centre-west of Morocco on the Atlantic coast. The energy takes the maximum value at 12:45 which varies between $753 \mathrm{~W} / \mathrm{m}^{2}$ during the period of December and $911 \mathrm{~W} / \mathrm{m}^{2}$ during the month of June. This is due to the movements of earth, that is to say, the annual movement of revolution around the sun and the daily movement of rotation around its axis. Since solar radiation arrives onto the Earth as a parallel beam, a surface perpendicular to these rays intercepts the maximum energy density. In case we incline the surface from this perpendicular position, illumination decreases. The photovoltaic installation is composed of 6 photovoltaic panels, with an inclination equal to the latitude of the place. The power produced by these panels is apparent in Fig. 4; the relation between the daily global radiation and the power produced is linear. This power can reach $1389.3 \mathrm{~W}$ in December and $1680.8 \mathrm{~W}$ in June. PV module performance is strongly influenced by climatic conditions, specifically solar irradiance, and also by the duration of sunshine that influences the desalination unit operating time. During the night time solar PV and desalination system will not work for the reason that all the electrical energy produced is used to run the pump so as to produce fresh water; that means we have no energy storage.

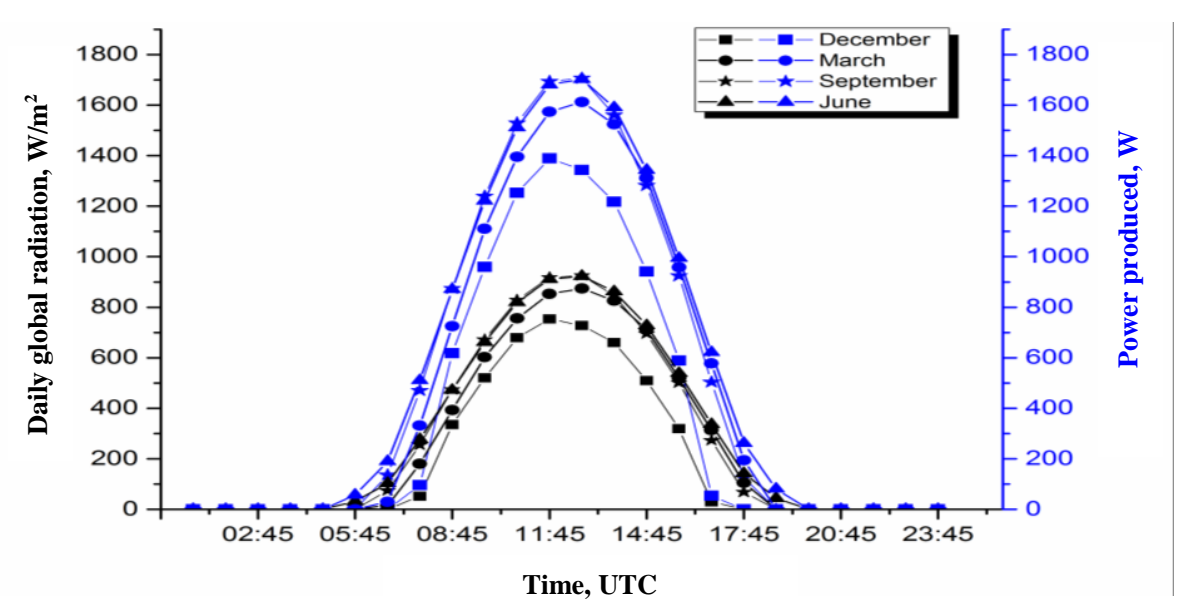

Fig. 4. Daily global radiation and electric power produced by the photovoltaic panels in Casablanca. 


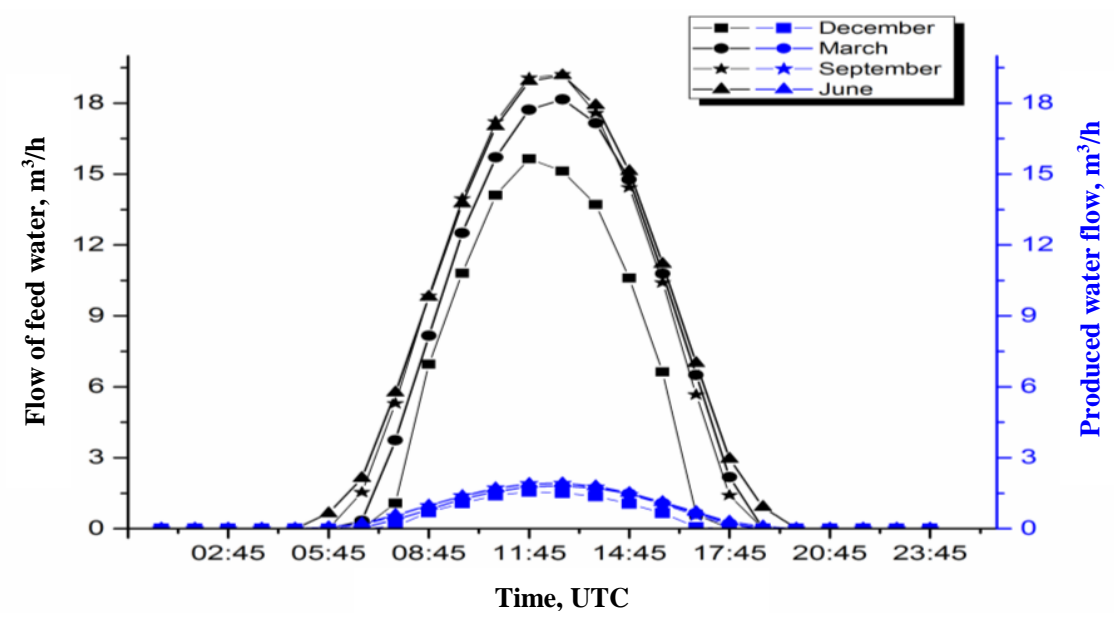

Fig. 5. Flow rate of feed water and produced water flow for a $C_{\mathrm{a}}=2 \mathrm{~g} / \mathrm{l}$ concentration and a conversion rate $\mathrm{y}=10 \%$ in Casablanca.

Water and energy are two key elements of sustainable development and they must be recognized as such. Water supply and energy supply are intimately linked. Decisions made in one area affect the other. Increase in the feed rate results in a decrease in the conversion rate, but, at the same time, it increases the production rate. Therefore, it can be said that high feed rates lead to high mass transfer coefficients.

Fig. 5 represents, respectively, the feed water flow and fresh water flow rates produced: for a concentration $C_{\mathrm{a}}=2 \mathrm{~g} / \mathrm{l}$ and a conversion rate $y=10 \%$, the maximum flow rates of the feed water. Fresh water in December produced $15.6 \mathrm{~m}^{3} / \mathrm{h}$ and $1.5 \mathrm{~m}^{3} / \mathrm{h}$, and the production for this month is $9.5 \mathrm{~m}^{3} /$ day. The concentration of feed water, that is, brackish water, effects feed water and freshwater flows.

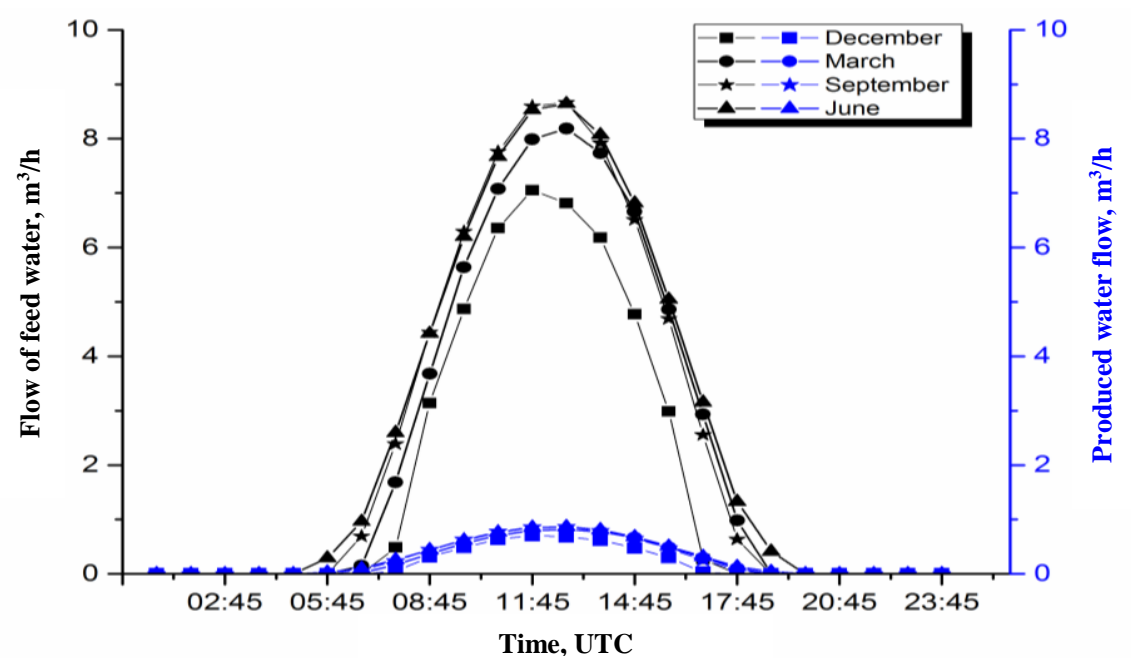

Fig. 6. Flow of feed water and produced water flow for a concentration $C_{\mathrm{a}}=6 \mathrm{~g} / \mathrm{l}$ and a conversion rate $y=10 \%$ in Casablanca. 


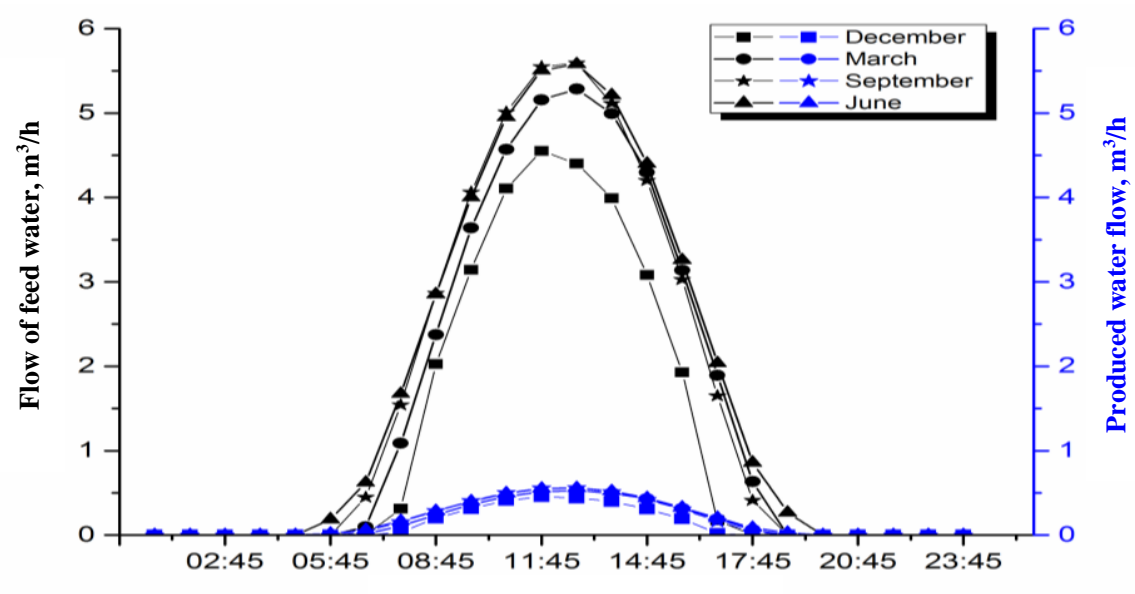

Time, UTC

Fig. 7. Flow of feed water and produced water flow for a concentration $C_{\mathrm{a}}=10 \mathrm{~g} / \mathrm{l}$ and a conversion rate $y=10 \%$ in Casablanca.

In fact, increase in the feed concentration causes an increase in the osmotic pressure which corresponds to an osmotic counter pressure causing a decrease in the effective pressure. At constant transmembrane pressure, the flux then decreases. On the other hand, increase in the concentration can cause an increase in concentration polarization at the level of the membrane-solution interface as it can accentuate, in a non-systematic way, clogging by gelling or precipitation of solutes.

In Fig. 6 and Fig. 7, we have the same electric power supply and decrease in the feed water flow; we can explain this observation by the osmotic pressure which increases with the concentration of the brackish water influencing the pressure required for the operation of the system. This result encourages the use of photovoltaic energy for desalination of brackish water because the energy consumed for desalination is lower than the seawater that contains significant amounts of salt.

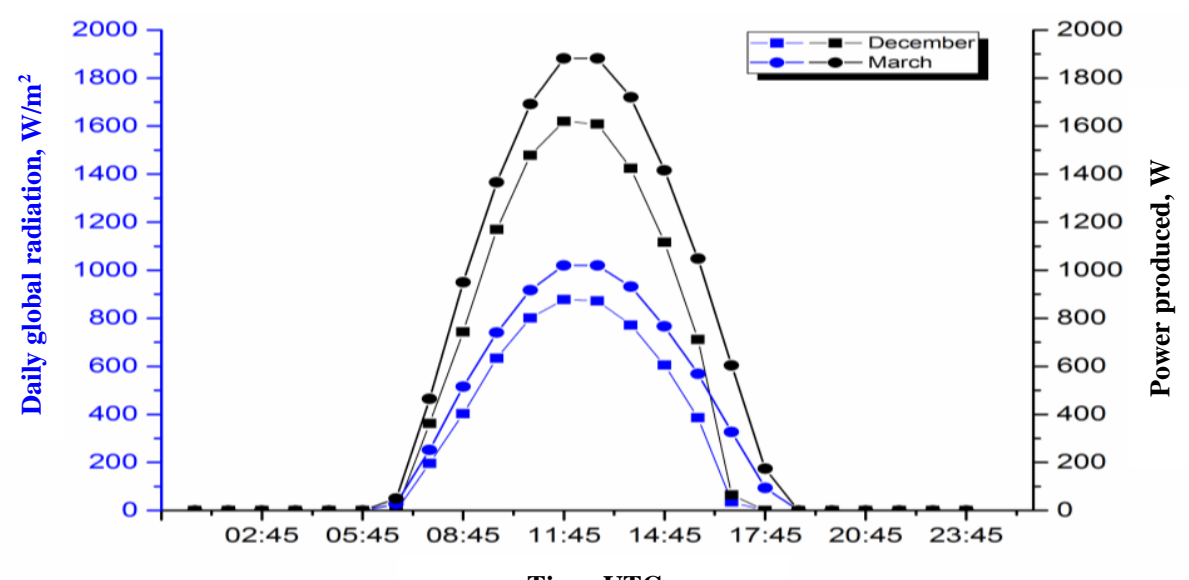

Time, UTC

Fig. 8. Daily global radiation and electric power produced by the photovoltaic panels in Ouarzazate. 


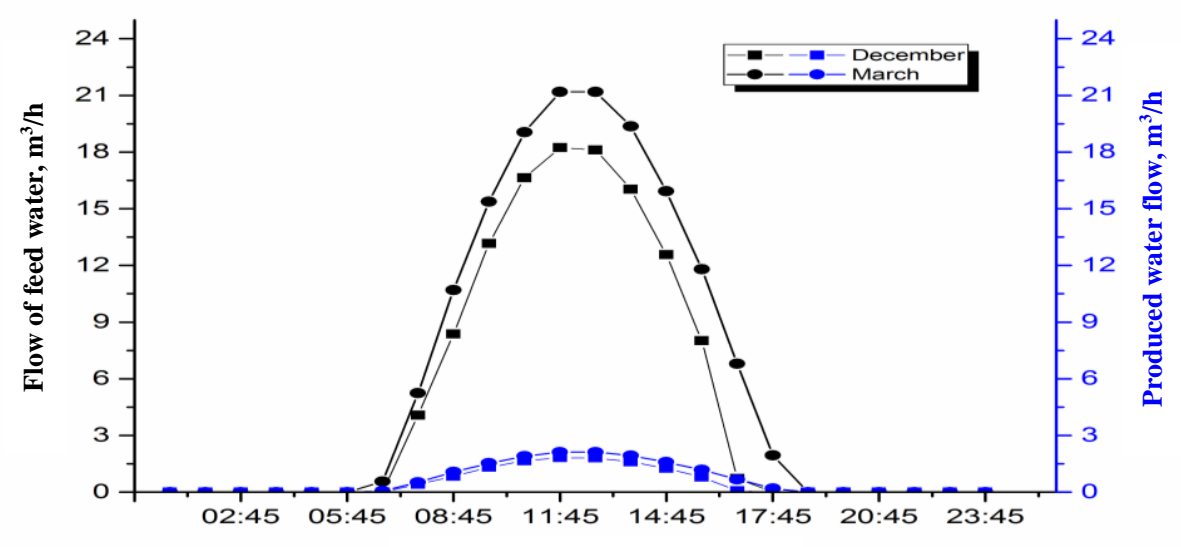

Time, UTC

Fig. 9. Flow rate of feed water and produced water flow for a $C_{\mathrm{a}}=2 \mathrm{~g} / \mathrm{l}$ and a conversion rate $y=10 \%$ in Ouarzazate.

The city of Ouarzazate is a Moroccan solar capital. This city's geographical position and climate give a real advantage that is to be exploited. The sun being present nearly 300 days in the region, solar projects that have already been launched are implemented in city of Ouarzazate for the quality of its sunshine.

Fig. 8 and Fig. 9 show the warm desert climate in Ouarzazate; in order to compare results with the previous (City of Casablanca), we take the same operating parameters and also the concentration of brackish water $C_{\mathrm{a}}=2 \mathrm{~g} / \mathrm{l}$; we can produce $1.8 \mathrm{~m}^{3} / \mathrm{h}$ as maximum value at noon. We note that there is an increase in freshwater produced as a result of insolation conditions in the installation site. Furthermore, we found that brackish water is lower in salinity and requires less energy than seawater during desalination.

\section{Conclusions}

The design and simulation of our reverse osmosis desalination prototype powered by photovoltaic solar energy makes us arrive at the following conclusions:

- The location of installation influences productivity of the system due to sun conditions;

- The brackish water concentration $C_{\mathrm{a}}=10 \mathrm{~g} / \mathrm{l}$; we can produce $0.4 \mathrm{~m}^{3} / \mathrm{h}$ as a maximum value of fresh water in the period of December;

- $C_{\mathrm{a}}=10 \mathrm{~g} / \mathrm{l}$ we can produce $0.4 \mathrm{~m}^{3} / \mathrm{h}$ as a maximum value of fresh water in December;

- The concentration of brackish water has a major role in the amount of energy consumed to produce one $\mathrm{m}^{3}$ of fresh water.

To conclude, the RO process does not involve a phase change that must have lower energy consumption than other separation processes such as distillation.

Table 7 summarizes the specific energy consumed for different concentrations, for the city of Casablanca with a conversion rate of $y=10 \%$. 


\section{TABLE 7. SPECIFIC ENERGY CONSUMED FOR DIFFERENT CONCENTRATIONS}

\begin{tabular}{ll}
\hline Concentration, g/l & Specific energy in $\mathrm{kWh} / \mathrm{m}^{3}$ \\
\hline 2 & 0.88819444 \\
4 & 1.42916667 \\
6 & 1.97013889 \\
10 & 3.05208333 \\
\hline
\end{tabular}

To sum up, reverse osmosis desalination powered by photovoltaic solar energy can be promoted by carrying out the following recommendations:

- Encourage understanding of how solar energy could be used for two purposes, electricity and freshwater, and its particular benefits for rural and remote areas, while contributing to environmental preservation;

- Demonstrate how a massive use of desalination using solar photovoltaic energy can be profitable by reducing dependence on imports of fossil fuels, improving the trade balance of countries (particularly in our case Morocco) which are currently dependent on imports of fossil fuels, while improving their energy independence and energy security.

\section{REFERENCES}

[1] Hot issues: water scarcity [Online]. [Accessed: 28.03.2015]. Available: http://www.fao.org/nr/water/issues/scarcity.html

[2] Escobar I. C. Chapter 14 Conclusion: A Summary of Challenges Still Facing Desalination and Water Reuse. Sustainability Science and Engineering 2010:2:389-397. doi:10.1016/S1871-2711(09)00214-1.

[3] ONEP. National Office of Potable Water, Non-conventional waters use for drinking water supply. Internal Report, 1996.

[4] U.S. Department of the Interior, Bureau of Reclamation and Sandia National Laboratories. Desalination and Water Purification Roadmap - A Report of the Executive Committee [Online]. Available: http://wrri.nmsu.edu/tbndrc/roadmapreport.pdf

[5] Byrne P., et al. A review coupling of cooling, desalination and solar photovoltaic systems. Renewable and Sustainable Energy Reviews 2015:47:703-717. doi:10.1016/j.rser.2015.03.08

[6] Latosov E., Volkova A., Siirde A., Thalfeldt M., Kurnitski J. The Impact of Parallel Energy Consumption on the District Heating Networks. Environmental and Climate Technologies 2019:23(1):1-13. doi:10.2478/rtuect-2019$\underline{0001}$

[7] Ghaffour N., Missimer T. M., Amy G. L. Technical review and evaluation of the economics of water desalination: current and future challenges for better water supply sustainability. Desalination 2013:309:197-207. doi:10.1016/j.desal.2012.10.015

[8] Zotalis K., et al. Desalination technologies: Hellenic experience. Water 2014:6(5):1134-1150. doi:10.3390/w6051134

[9] Banat F., Qiblawey H., Al-Nasser Q. Design and Operation of Small-Scale Photovoltaic-Driven Reverse Osmosis (PV-RO) Desalination Plant for Water Supply in Rural Areas. Computational Water, Energy, and Environmental Engineering 2012:1:31-36. doi:10.4236/cweee.2012.13004

[10] Fritzmann C., Loewenberg J., Wintgens T., Melin T. State-of-the-art of reverse osmosis desalination. Desalination 2007:216(1-3):1-76. doi:10.1016/j.desal.2006.12.009

[11] Outzourhit A., Elharrak N., Abouirass M., Mokhlisse A. Autonomous desalination units for fresh water supply in remote rural areas. Technological Perspectives for Rational Use of Water Resources in the Mediterranean Region 2009:157-162.

[12] Alghoul M. A., et al. Design and experimental performance of brackish water reverse osmosis desalination unit powered by $2 \mathrm{~kW}$ photovoltaic system. Renewable Energy 2016:93:101-114. doi:10.1016/j.renene.2016.02.015

[13] Ministry of Energy. Brackish groundwater in Morocco. Potentialities as alternative resources. Morocco: MEM, 2008.

[14] The Institute of Energy and the Environment of Francophonie (IEPF) [Online]. Available: https://www.ifdd.francophonie.org/reseaux/mediaterre/index.php 
[15] Masen [Online]. Available: www.masen.ma

[16] Phillipe A., Moulin P. Microfiltration and ultrafiltration: conduct pilot tests, DE. French Club of membranes, 2002.

[17] Bouroche Le Bras A.-M. Membrane separation techniques. French vocabulary-English-German. Paris: INRA, 1994.

[18] Marty P. Treatment of effluents by membrane filtration and agricultural. Industries Alimentaires et Agricoles, 1999.

[19] Noble R. D., Sterns A. Membrane separations technology; principles and applications. Elsevier, 1995.

[20] Bimbenet J. J., Albert D., Gilles T. Food process engineering; bases to applications. Paris: Dunod, 2002.

[21] Aimar P., Dauphin G., Rene F. Membrane separations in the processes of the food industry. Techniques and documentation. Lavoisier, 1998.

[22] Snyder S. A., et al. Role of membranes and activated carbon in the removal of endocrine disruptors and pharmaceuticals. Desalination 2007:202(1-3):156-181. doi:10.1016/j.desal.2005.12.052

[23] Juang L. C., Tseng D. H., Lin H. Y. Membrane processes for water reuse from the effluent of industrial park wastewater treatment plant: a study on flux and fouling of membrane. Desalination 2007:202(1-3):302-309. doi:10.1016/j.desal.2005.12.068

[24] World Health Organization. Guidelines for drinking-water quality: incorporating 1st and 2nd addenda, Recommendations. Geneva: WHO Press, 2008.

[25] Bzioui M. National Report 2004 on water resources in Morocco. Water-Africa, 2004.

[26] Meihong L., Zhenhua L., Zhihai C., Sanchuan Y., Congjie G. Comparison of reverse osmosis and nanofiltration membranes in the treatment of biologically treated textile effluent for water reuse. Desalination 2011:281:372-378 doi:10.1016/j.desal.2011.08.023

[27] Elazhar F., Zouhri N., Ait habzize S., Taky M., Elmidaoui A. Study of Atlantic seawater desalinization by reverse osmosis using a pilot plant. Physical and Chemical News 2011:58:20-24.

[28] Khalifa A., et al. Experimental and theoretical investigations on water desalination using direct contact membrane distillation. Desalination 2017:404:22-34. doi:10.1016/j.desal.2016.10.009

[29] Burn S., et al. Desalination techniques - A review of the opportunities for desalination in agriculture. Desalination 2015:364:2-16. doi:10.1016/j.desal.2015.01.041

[30] Miller S., Shemer H., Semiat R. Energy and environmental issues in desalination. Desalination 2015:366:2-8. doi:10.1016/j.desal.2014.11.034

[31] Weng C. H., Sharma Y. C., Chua S. H. Adsorption of Cr(VI) from aqueous solutions by spent activated clay. Journal of Hazardous Materials 2008:155(1-2):65-75. doi:10.1016/j.jhazmat.2007.11.029

[32] Tahir S. S., Rauf N. Removal of cationic dye from aqueous solutions by adsorption onto bentonite clay. Chemosphere 2006:63(11):1842-1848. doi:10.1016/j.chemosphere.2005.10.033

[33] Xevgenos D., Moustakas K., Malamis D., Loizidou M. An overview on desalination \& sustainability: renewable energy-driven desalination and brine management. Desalination and Water Treatment 2016:57(5):2304-2314. doi:10.1080/19443994.2014.984927

[34] Giles C. H., Smith D., Huitson A. A General Treatment and Classification of the Solute Adsorption Isotherm. I. Theoretical. Journal of Colloid and Interface Science 1974:47(3):755-765. doi:10.1016/0021-9797(74)90252-5

[35] Markovska L., Meshko V., Noveski V., Marinovski M. Solid diffusion control of the adsorption of basic dyes onto granular activated carbon and natural zeolite in fixed bed columns. Journal of the Serbian Chemical Society 2001:66(7):463-475. doi:10.2298/JSC0107463M

[36] Renaudin V. Desalination of seawater and brackish water. Nancy Brabois: Educsol, 2003.

[37] Tata-Ducru F. Seawater desalination: review of the latest advances technological; economic balance sheet; critical analysis according to contexts. Paris, 2009.

[38] Greenlee L. F., et al. Reverse osmosis desalination: Water sources, technology, and today's challenges. Water Research 2009:43(9):2317-2348. doi:10.1016/j.watres.2009.03.010

[39] Metaiche M. Technologie membranaire. Bouira: Universite de Bouira, 2014.

[40] Tansakul C. Hybrid Membrane Processes for Pretreatment of Water from sea before desalination by reverse osmosis. Toulouse: University of Toulouse, 2009.

[41] Baker J. S. Judd S. J. Parsons S. Antiscale magnetic pretreatment of reverse osmosis feedwater. Desalination 1997:110(1-2):151-165. doi:10.1016/S0011-9164(97)00094-5

[42] Khiari W., Turki M., Belhadj J. Experimental prototype of a reverse osmosis desalination system powered by an intermittent renewable source without electrochemical storage. "Design and characterization for Energy-water management". International Conference on Electrical Sciences and Technologies, Maghreb, 2016. doi:10.1109/CISTEM.2016.8066819

[43] Alkhatib A. Reverse-Osmosis Desalination of Water Powered by Photo-Voltaic Modules. Computational Water, Energy and Environmental Engineering 2014:3(1):22-29. doi:10.4236/cweee.2014.31003

[44] Photovoltaic modules. Turbo 300-320 W. Available: www.eurenergroup.com

[45] Wijmans J. G., Baker R. W. The solution-diffusion model: a review. Journal of Membrane Science 1995:107(1-2):121. doi:10.1016/0376-7388(95)00102-I

[46] Lee S., Lueptow R. M. Membrane Rejection of Nitrogen Compounds. Environmental and Science Technologies 2001:35(14):3008-3018. doi:10.1021/es0018724 
[47] Wang X., Tang Y. Exergetic analysis on the two-stage reverse osmosis seawater desalination system. Desalination and Water Treatment 2013:51:2862-2870. doi:10.1080/19443994.2012.750809

[48] Sassi K. M., Mujtaba I. M. Simulation and Optimization of Full Scale Reverse Osmosis Desalination Plant. Computer Aided Chemical Engineering 2010:28:895-900. doi:10.1016/S1570-7946(10)28150-6

[49] Aybar H. S., et al. Solar Powered RO Desalination: Investigations on Pilot Project of PV Powered RO Desalination System. Applied Solar Energy 2010:46(4):275-284. doi:10.3103/S0003701X10040080

[50] McCutcheon J. R., McGinnis R. L., Elimelech M. Desalination by ammonia-carbon dioxide forward osmosis: Influence of draw and feed solution concentrations on process performance. Journal of Membrane Science 2006:278(1-2):114-123. doi:10.1016/j.memsci.2005.10.048

[51] Adda A., Naceur W. M., Abbas M. Modeling and optimization of the energy consumption of a reverse osmosis desalination plant in Algeria. Revue des Energies Renouvelables 2016:19(2):154-164.
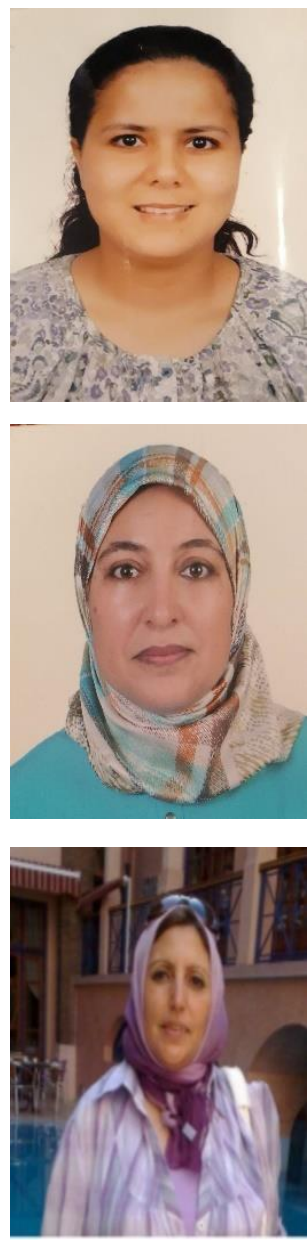

Hind Ennasri acquired Bachelor's degree of physics in 2010, and Master's degree of renewable energy and energy systems in 2012 from Hassan II University, Faculty of Science of Ain Chock in Casablanca, Morocco.

She conducts continuous research in the energy field. Currently, she is a $\mathrm{PhD}$ student at Hassan II University, Faculty of Science Ben M'Sik in Casablanca, Morocco. Her main research area of interest is the application and improvement of solar energy-based systems. ORCID ID: https://orcid.org/0000-0001-5335-9955

Dr. Asmaa Drighil received Ph.D. degree of physics materials in 2000, from Hassan II University, Faculty of Science Ben M'Sik in Casablanca, Morocco.

She is currently a professor in the department of physics, in the faculty of sciences Ben M'sick, University Hassan II Casablanca. Her main research area is the field of Engineering Science.

Dr. Rahma Adhiri has a doctoral degree and state thesis of physics materials in 2000 from the Hassan II University, Faculty of Science Ben M'Sik in Casablanca, Morocco.

She is currently a professor in the department of physics, in faculty of sciences Ben M'sik, Hassan II University of Casablanca. The main scientific activities fall within the field of Engineering Science in general and the physics of materials in particular. She covers the following areas: technology diffusion, implementation and processing in microelectronics, materials development by various deposition methods, structural and morphological analysis. 

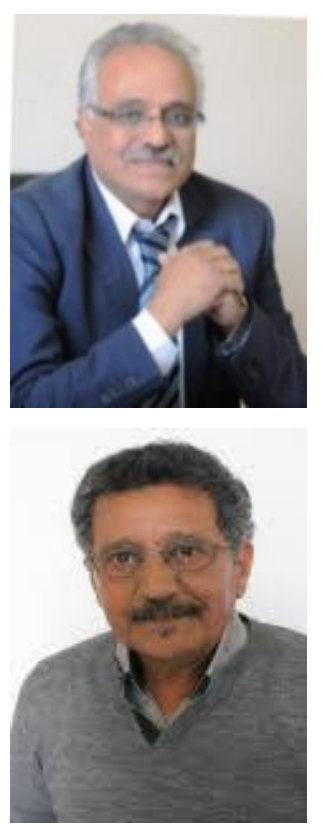

Dr. Ahmed Fahli, a Professor; he has a doctoral degree "Transition between the phenomena governed by the main and hollow field governed by the nucleon collisions in the $40 \mathrm{Ar}+68$ Zn reaction" in 1986 from the Louis Pasteur University of Strasbourg I, National Institute of Nuclear Physics and Particle Physics, Strasbourg, France.

Currently is a vice president for scientific research and cooperation of Hassan I University of Settat, Morocco, and he is a member of laboratory of engineering and materials at University of Hassan II, Faculty of Science Ben M'Sik in Casablanca, Morocco.

Dr. Mohamed Moussetad has two steps, holder of doctoral degree "Measurement X-ray crystallography on single crystal industrial application" in 1987 from the University of Franche-Comté, Faculty of Science and Technology, Besancon, France, and state thesis in 2000 from Hassan II University, Faculty of Science, Ben M'Sik in Casablanca, Morocco. $\mathrm{He}$ is currently a professor in the department of physics, head of research team "Materials and thin layers" and assistant director of the laboratory of engineering and materials, in faculty of sciences Ben M'sik, Hassan II University Casablanca, Morocco. The main research area is material development and development of analytical techniques. 